\title{
A robust hierarchical model of daily stream temperature using air-water temperature synchronization, autocorrelation, and time lags
}

Benjamin H Letcher, Daniel J Hocking, Kyle O'Neil, Andrew R Whiteley, Keith H Nislow, Matthew J O'Donnell

Water temperature is a primary driver of stream ecosystems and commonly forms the basis of stream classifications. Robust models of stream temperature are critical as the climate changes, but estimating daily stream temperature poses several important challenges. We developed a statistical model that accounts for many challenges that can make stream temperature estimation difficult. Our model identifies the yearly period when air and water temperature are synchronized, accommodates hysteresis, incorporates time lags, deals with missing data and autocorrelation and can include external drivers. In a small stream network, the model performed well (RMSE $=0.59^{\circ} \mathrm{C}$ ), identified a clear warming trend $\left(0.63{ }^{\circ} \mathrm{C} \cdot\right.$ decade $\left.^{-1}\right)$ and a widening of the synchronized period (29 $\mathrm{d}$. decade $\left.^{-1}\right)$. We also carefully evaluated how missing data influenced predictions. Missing data within a year had a small effect on performance $(\sim 0.05 \%$ average drop in RMSE with $10 \%$ fewer days with data). Missing all data for a year decreased performance $\left(\sim 0.6^{\circ} \mathrm{C}\right.$ jump in RMSE), but this decrease was moderated when data were available from other streams in the network. 
1

2

3

4

5

6

7

8

9

10

11

12

13

14

15

16

17

18

19

20

21

22

23

24 Corresponding author: Benjamin H. Letcher, bletcher@usgs.gov
${ }^{1}$ S.O. Conte Anadromous Fish Research Center US Geological Survey/Leetown Science Center

Turners Falls, Massachusetts 01376 USA

${ }^{2}$ Department of Environmental Conservation

University of Massachusetts, Amherst, MA 01003-4210 USA

${ }^{3}$ Northern Research Station

USDA Forest Service

University of Massachusetts, Amherst, MA 01003-4210 USA 


\section{Abstract}

27 Water temperature is a primary driver of stream ecosystems and commonly forms the basis of stream classifications. Robust models of stream temperature are critical as the climate changes, but estimating daily stream temperature poses several important challenges. We developed a statistical model that accounts for many challenges that can make stream temperature estimation difficult. Our model identifies the yearly period when air and water temperature are synchronized, accommodates hysteresis, incorporates time lags, deals with missing data and autocorrelation and can include external drivers. In a small stream network, the model performed well $\left(\right.$ RMSE $=0.59^{\circ} \mathrm{C}$ ), identified a clear warming trend $\left(0.63{ }^{\circ} \mathrm{C} \cdot\right.$ decade $\left.^{-1}\right)$ and a widening of the synchronized period $(29 \mathrm{~d} \cdot$ decade $^{-1}$ ). We also carefully evaluated how missing data influenced predictions. Missing data within a year had a small effect on performance $(\sim 0.05 \%$ average drop in RMSE with $10 \%$ fewer days with data). Missing all data for a year decreased performance $\left(\sim 0.6^{\circ} \mathrm{C}\right.$ jump in RMSE), but this decrease was moderated when data were available from other streams in the network.

\section{Introduction}

Accurate stream temperature predictions are increasingly important as human impacts on streams and on the climate accelerate stream temperature change (Kaushal et al., 2010; Rice \& Jastram, 2014). Human activities influence stream temperatures directly via increased water withdrawals, altered channel engineering and dam operation (Poole \& Berman, 2001) and indirectly by altering landscape features (e.g. riparian cover) and by affecting air temperatures at broad spatial scales via climate change (Hayhoe et al., 2007; Huntington et al., 2009). Understanding how stream temperatures are changing over time and space and the ability to forecast future temperatures are important because stream temperatures directly influence stream ecosystems (Quinn et al., 1994; Wenger et al., 2011) and because regulatory agencies commonly use stream temperature as a metric for managing streams and their watersheds (e.g. Beauchene et al., 2014). Altered stream temperatures are likely to have profound effects on the abundance and distribution of 
55

56

57

58

59

60

61

62

63

64

65

66

67

68

69

70

71

72

73

74

75

76

77

78

79

80

81

82

83

84

stream biota (Isaak \& Rieman, 2012; Eby et al., 2014), especially coldwater, ectothermic species because many physiological and demographic rates are temperature-dependent (Fry, 1971; Elliott \& Elliott, 2010; Letcher et al., 2015).

The general importance of stream temperature has prompted the development of a number of models for stream temperature (e.g. Mohseni, Stefan \& Erickson, 1998; Caissie, El-jabi \& Satish, 2001; Hague \& Patterson, 2014; Sun et al., 2014; Li et al., 2014). Stream temperature models vary along several important gradients, including model type (physical-statistical), temporal resolution (daily-yearly) and spatial resolution (local-broad spatial coverage). As with all models of complex systems, tradeoffs among these gradients usually limit models to highly-detailed, local models (Brown, 1969; Kim \& Chapra, 1997; Younus, Hondzo \& Engel, 2000) or simple, general models (e.g. Crisp \& Howson, 1982). The detailed, local models typically produce good accuracy (RMSE $\sim 1.0{ }^{\circ} \mathrm{C}$ ) but may not predict temperatures well outside of the local area, while the simple models generate moderate to poor accuracy (RMSE $\sim 1.5^{\circ} \mathrm{C}$ to $3.0^{\circ} \mathrm{C}$ ) across a broad spatial range. Models that aggregate over longer time intervals generally perform better (Stefan \& Preud'homme, 1993; Pilgrim, Fang \& Stefan, 1998; Webb, Clack \& Walling, 2003; Morrill, Bales \& Conklin, 2005), but even hourly models can perform well (Kanno, Vokoun \& Letcher, 2013). A careful consideration of six key temperature modeling issues may provide the basis for the development of effective daily stream temperature models of medium complexity.

First, the relationship between air temperature and stream temperature is non-linear at high and low air temperatures (Mohseni, Stefan \& Erickson, 1998), but for different reasons. At high air temperatures, evaporative cooling slows warming of stream water, while at low air temperatures, air temperatures can dip well below the water temperature freezing limit (Caissie, 2006; Webb et al., 2008). Air and water temperatures are no longer synchronized when air temperatures are near and below $0^{\circ} \mathrm{C}$, which can generate a poor relationship between air and stream temperatures and heterogeneity of variance across temperatures. Many simple statistical models use a non-linear model to describe the relationship between air and stream temperature (Mohseni, Stefan \& Erickson, 1998; Webb, Clack \& Walling, 2003; Kanno, Vokoun \& Letcher, 2013). Others use a linear model and limit analysis to the summer (Hilderbrand, Kashiwagi \& Prochaska, 2014) or to the ice- 
85

86

87

88

89

90

91

92

93

94

95

96

97

98

99

100

101

102

103

104

105

106

107

108

109

110

111

112

113

free period of the year (Stefan \& Preud'homme, 1993; Erickson \& Stefan, 2000), in an attempt to avoid the non-linear portions of the air-water temperature relationship. Time series (Caissie, El-Jabi \& St-Hilaire, 1998; Caissie, El-jabi \& Satish, 2001; Benyahya et al., 2007) or non-parametric models (Benyahya et al., 2008; Li et al., 2014) of stream temperature trends over time that include air temperature as a predictor as well as local, physical models (e.g. Sinokrot \& Stefan, 1993) can accommodate the non-linearity.

Second, accuracy can be improved when models account for hysteresis, a different relationship between air and water temperature in the spring (rising temperatures) vs. the fall (falling temperatures) (Mohseni, Stefan \& Erickson, 1998; Caissie, El-jabi \& Satish, 2001; Webb, Clack \& Walling, 2003). Seasonal hysteresis is often caused by influx of cool snow melt or rain water in the spring (Lisi et al., 2015) which depresses spring stream temperature/air temperature relationships relative to fall stream temperature/air temperature relationships (Webb \& Nobilis, 1997). Mohseni et al. (1998) observed that $43 \%$ of their study streams exhibited hysteresis; they addressed hysteresis by fitting separate non-linear curves to the rising and falling seasonal temperatures. Time series models with non-symmetric seasonal functions account for hysteresis by default (e.g. Li et al., 2014).

Third, due to thermal inertia, stream temperature does not respond instantaneously to changes in air temperature. Including lags in air temperature effects can improve estimates for models with short time scales (Benyahya et al., 2008; Webb, Stewardson \& Koster, 2010). The effects of time lags increase with stream depth (Stefan \& Preud'homme, 1993) and stream flow (Smith \& Lavis, 1975; Webb, Clack \& Walling, 2003). Time lags are a key component of time series modeling (Shumway \& Stoffer, 2006).

Fourth, while the amount of stream temperature data available worldwide is increasing very rapidly (Webb et al., 2008), many sites have incomplete data. Very few study regions have a complete matrix of sample sites and years: data may be missing for an entire year at a site or may be incomplete within a year. Incomplete within-year data will have variable effects on estimation depending on the extent and timing of the missing data. Effects of missing data will also depend on model type. For simple linear models, within-year missing 
114 data may not have a large effect on estimation because of the linear relationship between

115 stream and air temperature. For non-linear models, missing data could have dramatic

116 effects on estimation as missing data fail to 'anchor' the curve. Other modeling approaches,

117 such as time series models, machine learning models (DeWeber \& Wagner, 2014) , and

118 models with varying coefficients ( $\mathrm{Li}$ et al., 2014) may be less sensitive to missing data. In

119 general, hierarchical models with random effects across space (sites, stream networks or

120 regions) and time (months, seasons, or years) can accommodate missing data as they

121 'borrow information' across units (Wagner, Hayes \& Bremigan, 2006; Gelman \& Hill, 2007).

122 Fifth, spatial and temporal autocorrelation can cause estimation problems (Caissie, 2006;

123 Benyahya et al., 2007; Hague \& Patterson, 2014). Autocorrelation occurs when data points

124 in space or time are not independent, i.e. close points are similar or dissimilar to each other

125 simply because they are close. For example, downstream temperatures can be similar to

126 upstream temperatures because water flows downstream or today's temperature can be

127 similar to yesterday's temperature due to the combination of high heat capacity of water,

128 low density and heat transfer from air, and conduction of heat from surrounding

129 environment (i.e. thermal inertia) (Caissie, El-Jabi \& St-Hilaire, 1998; Isaak et al., 2014).

130 This is a very common issue in estimation and a variety of time series models can

131 accommodate temporal autocorrelation (Shumway \& Stoffer, 2006) and some newer

132 approaches are now available to deal with spatial autocorrelation (Peterson \& Ver Hoef,

133 2010; Rushworth et al., 2015).

134 Finally, air temperature is not the only important predictor of stream temperature (Webb, 135 1996; Caissie, 2006). Many regression-based models have evaluated effects of landscape 136 and environmental drivers on stream temperatures (Hawkins et al., 1997; Isaak \& Hubert, 137 2001; Hill, Hawkins \& Carlisle, 2013). Important landscape drivers typically include 138 topography, riparian cover, impervious surface, and stream depth (Poole \& Berman, 2001) 139 and environmental drivers often include stream flow, snow melt, groundwater input, and 140 humidity (Taylor et al., 2013; Lisi et al., 2015; Snyder, Hitt \& Young, 2015). It is generally 141 straightforward to incorporate external drivers beyond air temperature into most classes 142 of stream temperature models (Hague \& Patterson, 2014). 
143 Here, we develop a model for mean daily stream temperature that improves accuracy of

144 statistical models by addressing most of the issues listed above. To avoid fitting a

145 relationship between stream and air temperature when there is none (e.g. winter), we

146 develop a metric that limits estimation to the days of the year that daily stream

147 temperature and daily air temperature are synchronized (roughly spring to fall). This

148 metric is flexible among years and sites. To address hysteresis, we estimate a non-

149 symmetrical trend across the synchronized days with a hierarchical structure to

150 accommodate missing data. We also add an autoregressive term to the model to deal with

151 temporal autocorrelation and we estimate spatial covariance to accommodate spatial

152 autocorrelation. Because data presented here are spatially constrained to four sites in a

153 small network, we do not include landscape variables in the model. The two environmental

154 drivers in the model are air temperature and stream flow. In addition to presenting the

155 model, we analyze trends in estimates over time and conduct a detailed missing

156 observations analysis.

\section{Methods}

158 Study area

159 The study site was located in western Massachusetts, USA ( $42^{0} 25^{\prime} \mathrm{N} ; 72^{0} 39^{\prime}$ W, Fig. 1) and 160 consisted of a third-order mainstem (West Brook, WB) and three second-order tributaries 161 (Open large, OL; Open small, OS; Isolated large, IL) (Fig. 1 and Table 1). A dense canopy of 162 mixed hardwood with some hemlocks provides cover throughout the watershed.

163 Watershed area above our study area is $11.8 \mathrm{~km}^{2}$ and landuse in the area is limited 164 residential with some farming. The study is in an area of low to moderate relief, with 165 altitude ranging from to $100 \mathrm{~m}$ to $250 \mathrm{~m}$ (Fig. 1). Average stream width of the WB is $4.5 \mathrm{~m}$ 166 and is between 1-3 m for the tributaries. Water is stored in two of the streams; a drinking 167 water reservoir is upstream of the WB, and a large beaver dam complex is above OS (Fig. 168 1). OL and IL were free-flowing during the course of the study.

169 We deployed temperature loggers ( \pm 0.1 C; Optic StowAway and Hobo Pro V2, Onset 170 Computer Corporation, Pocasset, MA, USA, and \pm 0.05 C; Barologger, Solinst Canada Ltd.,

171 Georgetown, ON) in four permanently watered sections of the study area (Fig. 1). Stream 
172 temperature data are available at http://db.ecosheds.org. All loggers recorded data every 173 two hours throughout the year. The logger in the WB was deployed 1998 to 2013 and the 174 loggers in the tributaries were out from 2002 to 2013. We do not have continuous air 175 temperature measurements from 2002 to 2013 (Table 1), so we used mean daily air 176 temperature estimates for our study area from Daymet (http://daymet.ornl.gov/). For the 177 years that we do have West Brook air temperature data (2008-2013), the relationship 178 between West Brook and Daymet air temperatures was strong ( $\mathrm{p}$-value $<10^{-16}, \mathrm{r}^{2}=0.91$ ), 179 suggesting that Daymet air temperatures are a good data source for the study site. Stream flow was estimated using a flow extension model (Nielsen, 1999) based on data from a nearby $(\sim 10 \mathrm{~km})$ USGS stream gage (Mill River, Northampton, MA, U.S.A.). See (Xu, Letcher 182 \& Nislow, 2010) for details.

Statistical analysis

185

186

187

188

189

190

191

192

193

194

195

196

197

198

199

Descriptive statistics. As a coarse comparison of daily water temperatures, we calculated correlations among sites. We also explored patterns in water temperature over time and among sites by comparing cumulative residuals from a spline fit to all the data (function gam() in R, Fig. 2). We calculated residuals for each water temperature data point and then developed empirical cumulative curves over days of the year for each year and site combination.

Breakpoints. The goal is to develop a robust model for the relationship between mean daily water and mean daily air temperature. A key limitation in developing this relationship is that lower water temperatures in the winter are bounded near $0{ }^{\circ} \mathrm{C}$ while air temperatures are not. This means that water and air temperatures can become decoupled when air temperatures are cold resulting in only a weak relationship, at best, between water and air temperature. In contrast, as air temperatures warm in the spring and before they get too cold in the autumn, daily water and air temperatures can be synchronized (Fig. 3 above), suggesting the possibility of a strong relationship between daily water and air temperature during the synchronized portion of each year. 
200 The key to the approach is identifying a breakpoint in the spring when daily water and 201 daily air temperature become synchronized and a breakpoint in the autumn when daily 202 temperatures become desynchronized. To identify the synchronization breakpoints we 203 calculated a simple index (waterT - airT)/waterT (waterT $>0$ ), where waterT was mean 204 daily water temperature and airT was mean daily air temperature (Fig. 3). This temperature index (tempIndex) approaches 0 when water and air temperature are similar and is very different from 0 when temperatures diverge (Fig. 3). While water and air temperatures are synchronized, tempIndex flattens out (Fig. 3b), providing the opportunity to identify the beginning and end (breakpoints) of the flat period.

To identify the spring and autumn breakpoints, we used a runs analysis that determined the first (spring) and last (autumn) day of the year that the tempIndex was consistently within the flat period (Fig. 3). We established the range of tempIndex values that comprised the flat period by calculating the $99.9 \%$ confidence interval (CI) for tempIndex using the middle 150 days of the year (late April to mid-September). The middle 150 days of the year were always within the flat period based on visual observation of tempIndex plots. Separate CI values were calculated for each year and stream. For the breakpoint estimation, we used a moving average for tempIndex with a centered 10-day window to help stabilize tempIndex values near the breakpoints. Temperatures were considered synchronized when 10 consecutive days of the moving average fell within the $99.9 \% \mathrm{CI}$. Beginning on day 1 and moving towards day 150, the first time 10 consecutive days were synchronized was used as the spring breakpoint and we moved from the end of the year to day 150 to establish the fall breakpoint. Numbers of days in the synchronized period for each stream and year are shown in Table 2.

We evaluated trends in fall and spring breakpoints by running three linear models with breakpoint day of the year as the dependent variable and year alone or year + stream or year * stream as independent variables. We estimated AIC to determine the most parsimonious model.

Water temperature model description. With breakpoints established for each year and site, 228 we modeled the relationship between water temperature and air temperature for the 
229 synchronized period using a hierarchical linear autoregressive model with a cubic trend 230 across days within a year and covariation among sites. We fit the model using a Bayesian 231 approach.

232 Observed water temperature $\left(t_{s, d, y}\right)$ for each site $\left(s ; s_{1}=W B, s_{2}=O L, s_{3}=O S, s_{4}=I L\right)$, 233 day of year $(d)$ and year $(y)$ was assumed to derive from a normal distribution with mean $234 \mu_{s, d, y}$ and standard deviation $s d$ (residual model error):

$$
t_{s, d, y} \sim N\left(\mu_{s, d, y}, s d\right)
$$

Equation 1

236

We used a non-informative uniform prior $[0,10]$ for $s d$. We modeled the mean with a linear trend $\left(\omega_{s, d, y}\right)$ adjusted by an $\operatorname{AR}(1)$ autoregressive coefficient $\left(\delta_{s}\right)$ on the residual error from the previous day:

$$
\mu_{s, d, y}=\omega_{s, d, y}+\delta_{s}\left(t_{s, d-1, y}-\omega_{s, d-1, y}\right)
$$

Equation 2

We placed a hierarchical structure on $\delta_{S}$ :

$$
\delta_{s} \sim N\left(\mu \delta_{s}, s d \delta\right) T(-1,1)
$$

Equation 3

where site-specific $\delta_{s}$ were drawn from a truncated normal distribution with mean $\mu \delta_{s}$ and standard deviation $s d \delta$. Values for $\delta_{s}$ were truncated to keep them within the admissible range for a correlation. Priors for the mean and standard deviation were non-informative; $\mu \delta_{s} \sim U(-1,1)$, and $s d \delta \sim U(0,2)$ (an upper limit of 2 for $s d \delta$ is non-informative for the truncated data).

When observed temperature data were not available for the previous day (beginning of a series or following a break in the series) we modeled the mean without the autoregressive component:

$$
\mu_{s, d, y}=\omega_{s, d, y}
$$

Equation 4

We modeled the linear component with a combination of fixed and random effects: 
252

253

$\omega_{s, d, y}=\alpha+\beta_{1} T_{s, d, y}+\beta_{2} T_{s, d-1, y}+\beta_{3} T_{s, d-2, y}+\beta_{4} F_{s, d, y}+\beta_{5} T_{s, d, y} \cdot F_{s, d, y}+\beta_{6: 8} S+\beta_{9: 11}$ $s \cdot T_{s, d, y}+Y_{y}$ Equation 5

254

255

256

257

258

Parameter estimation

273 We used the program JAGS (http://mcmc-jags.sourceforge.net) to code the model and to where $\alpha$ is the overall intercept, the $\beta$ are the coefficients for the fixed effects ( $T$ is mean daily air temperature, $F$ is mean daily stream flow, $s$ is site) and $Y_{y}$ represents random effects among years. Priors for the $\beta_{1: 11}$ were independent and non-informative, $N(0,100)$.

$Y_{y}$ represented random effect temporal trends (cubic) across years where:

$$
Y_{y}=\alpha_{y}+\beta_{12, y} D_{s, y, d}+\beta_{13, y} D_{s, y, d}^{2}+\beta_{14, y} D_{s, y, d}^{3}
$$

Equation 6

$$
Y_{y}=X_{s, d, y} \mathrm{~B}_{y}
$$

Equation 7

where $\mathrm{X}$ is a data matrix with $l$ columns $(l=4$; the number of year-level predictors $)$ with the first column a vector of 1's for the intercept and $B_{y}$ is the $y \times l$ matrix of year-level regression coefficients. Priors for the mean were non-informative, with

$$
\mathrm{B}_{y} \sim M V N\left(M_{l}, \Sigma\right)
$$

Equation 8

where $M_{l}=\left(\mu_{\alpha}, \mu_{\beta 12,} \mu_{\beta 13}, \mu_{\beta 14}\right)$ is a vector of length $l$, representing the mean of the distribution of intercept and slopes. The $l x l$ covariance matrix is represented by $\Sigma$ where the variance of each regression coefficient is on the diagonal and the covariance on the offdiagonals. The hyperprior for the means were non-informative with $\mu_{\alpha,}=0$ and $\mu_{\beta 12,} \mu_{\beta 13 \text {, }}$ $\mu_{\beta 14} \sim N(0,100)$. Standard deviation priors were also non-informative and were drawn from an inv-Wishart distribution:

$$
\Sigma \sim \operatorname{inv}-\operatorname{wish}(\operatorname{diag}(l), l+1)
$$

Equation 9 draw posterior samples of the parameters (see supplemental material for JAGS code). We called JAGS from R (3.1.2) using the package 'rjags' (V 3-14)(Plummer, 2014). We ran three 
276 chains with 1000 burn-in and 2500 evaluation iterations. Chains were thinned to keep 277 every fifth iteration. We checked convergence using the 'potential scale reduction factor' 278 (Brooks \& Gelman, 1998) from the 'coda' package in R (Plummer et al., 2006) and also 279 assessed chains visually.

280 Model assessment

281 Goodness of Fit and prediction. We assessed goodness of fit in two ways. First, we compared 282 observed and predicted values for the complete dataset. Second, we ran a series of cross

283 284 285

286

287 288 289 290 validation tests where we randomly left out a portion of the water temperature data, estimated parameters with the remaining (training) data and compared predictions of the left out (testing) data to original values. This involved leave-p-out cross-validation where we randomly left out a proportion (p) of the data, where $\mathrm{p}=0,0.05,0.1,0.2,0.3,0.4,0.5$, $0.6,0.7,0.8$. We ran 10 replicates for each value of $\mathrm{p}$. For each condition, we calculated the root mean square error (RMSE) of the residuals for the training and the test data sets.

Missing data

We also ran a series of tests to ask how the quantity, timing, and location of missing data influenced model performance (estimation and prediction). These tests can be used to help understand performance and to help design monitoring strategies. This set of analyses differed from the leave-p-out cross-validation (above) because data were not left out randomly. Rather, consecutive days of data were left out, either within a year or across streams, reflecting the character of missing field data.

Quantity: To evaluate how increasing the number of sampling days within a year affects estimation and prediction, we left out increasing numbers of days on either side of the median sampling date for each stream and year combination. Specifically, we started with complete data and then conducted nine sets of runs where we left out data $15 \cdot d$ days from the beginning and 15. $d$ days from the end of each time series (where $d=1$ to 9), generating shorter time series by 30 days for each scenario.

When: We assessed how changing the timing of missing data affected predictions by shifting the window of available data from the beginning to the end of the synchronized 
304 period. To do this, we left out data for all but 30 consecutive days at a time for 13 non-

305

306

307

308

309

310

311

312

313

314

315

316

317

318

319

320

321

322

323

324

325

326

327

328

329

330

331

overlapping scenarios with scenario one starting at day of year 70 and scenario 13 starting at day of year 310 .

Where: To evaluate how well the model predicted stream temperatures when data were missing from one or more streams, we ran the above analyses leaving out data yearly from all streams or just the West Brook. For years with data just from the West Brook (19992002), we removed all data a year at a time. For years with data from the tributaries and the West Brook (2003 - 2013), we either removed all the data for each year (all four streams) or just the data from the West Brook for each year. Removing all the data for a given year tests how well the model predictions work when there are no data for the year (but there are data for other years), while removing data for just the West Brook tests how well predictions work when data are missing for a stream (but there are data for other streams and years).

For all tests, we compared RMSE of the residuals for the test (left out) data to the RMSE of the residuals of the full training set (base case).

\section{Results}

Descriptive statistics. Evaluation of the descriptive statistics suggested that water temperatures were similar for OL and IL and for WB and OS and that the streams appear to be warming over the duration of the study. Correlations of daily water temperatures among the four sites were all between 0.96 and 0.97 , except for the correlation between OL and IL (0.99). Patterns in the cumulative water temperature residuals were generally similar for WB and OS, with cooler years in the beginning of the time series and warmer years later (Fig. 4). OS demonstrated the warmest temperatures, especially in 2010-2012. Patterns were remarkably similar between OL and IL, also demonstrating generally cooler temperatures earlier in the data time series (Fig. 4). Monthly distributions of water temperature were highly variable across years and streams (Fig. S1).

Parameter estimation: Potential scale reduction factor (R-hat) values for all parameters were less than 1.01, indicating good convergence (Brooks \& Gelman, 1998). Parameter 
332 estimates gave an overall mean of 15.1, with strong air temperature effects (1.52 unlagged, 3330.20 lagged 1 day, 0.15 lagged 2 days), a positive effect of stream flow (0.36), and strong 334 site differences (OL $=-0.50, \mathrm{OS}=0.59$, IL $=-0.54$ ) (Fig. 5 and Table S1). The autoregressive 335 mean equaled 0.79 and there was little variation in the autoregressive terms among sites 336 (Fig. 5). The estimate for residual model error from Eq. 1 was 0.77.

337

338

340

341

342

343

344

345

346

347

348

349

350

351

352

353

354

355

356

357

358

359

360

Model assessment: Goodness of Fit and prediction. Using the full dataset, predicted values were very similar to observed values (Fig. S2). The slope of the relationship was 0.99 (s.e. = 0.0064 ) with an intercept of 0.15 (s.e. $=0.089$ ) and an $\mathrm{R}^{2}$ of 0.98 . Overall RMSE was $0.59 \pm$ 0.09 (Table 3). For the cross-validation tests where we randomly left out $30 \%$ of the data, the RMSE increased to $0.69 \pm 0.003$ for the training data and to $0.86 \pm 0.010$ for the test data (Table 3).

Across a broader range of data randomly left out (0 to 0.8), the RMSE for the test data increased approximately linearly with a 0.025 increase in RMSE for each 0.1 increase in proportion of data left out $\left(r^{2}=0.98\right.$; Fig. S3). RMSE for the training data set was largely insensitive to the proportion of data left out and had a mean value of 0.86 (s.d. $=0.016$, Fig. S3).

Break point trends. Break points appear to be getting later in the year in the fall and earlier in the year in the spring (Fig. 6). In the fall, delta AIC values for the linear models were all within two so we selected the simplest model (year only). In the spring, the delta AIC value for the simplest model was 5.2 so we also selected the simplest model (year only). Both seasons showed significant changes in breakpoints over years (estimate $=1.33, \mathrm{~F}(1,40)=$ 4.68, $\mathrm{p}$-value $=0.036$ fall; estimate $=-1.61, \mathrm{~F}(1,40)=9.13$, $\mathrm{p}$-value $=0.0045$ spring $)$, but year explained only 10\% (fall) or 19\% (spring) of the variation in the relationship. The parameter estimates indicated that breakpoints are 16 days earlier in the spring and 13 days later per decade in the fall, generating an estimated widening of the breakpoint window of 29 days per decade.

Trends in cubic functions. Predicted mean water temperatures based on the cubic function (Eq. 7) varied among years (Fig. S4), mirroring the general trend in the raw data (Fig. 2). Yearly maximum water temperature (white dots in S4) increased over the course of the 
361 study $\left(F=5.34, d f=1,13, p\right.$-value $\left.=0.037, R^{2}=0.24\right)$, with an estimated decadal increase of

$3620.63{ }^{\circ} \mathrm{C}$ (Fig. 7, above). In contrast, the day of year of the temperature maximum did not 363 change over the course of the study ( $F=0.030, d f=1,13$, p-value=0.86)(Fig. 7, below).

364 Missing data: Quantity. Adding more data to either side of the median date improved 365 predictions of the test data (filled circles in Fig. 8). The slope of the regression $(-0.46$, s.e. $=$ 3660.035 ) indicated that a $10 \%$ increase in data resulted in a reduction in RMSE of 0.046.

367 Missing data: When. The timing of data availability had a threshold effect on RMSE, with 368 relatively high and variable RMSE before day 160 and consistent lower RMSE after day 160 369 (triangles in Fig. 9).

370 Missing data: Where. Compared to the base case (all data included), leaving data out of the 371 estimation one year at a time resulted in a mean increase in RMSE of $0.48^{\circ} \mathrm{C}$ when just the

372 WB data were left out and a mean increase of $0.57^{\circ} \mathrm{C}$ when data for all four streams were 373 left out (Table 3).

374 As the amount of data was increased on either side of the median date, RMSE increased less 375 from the base case when data were available from the other three streams than when data 376 were not available for any of the streams. The slope of the relationship between the 377 proportion of days included in the training data and the difference in mean RMSE was -0.46 378 when just the WB data were left out and the slope was -0.63 (s.e. $=0.20$ ) when data from all 379 streams were left out (Fig. 8). The slopes suggest either a 0.046 or a 0.063 decrease in 380 RMSE with a 10\% increase in days included in the estimation.

381 When data were available for only 30 days, but the 30-day window of availability varied 382 across the year, the presence of data from the other streams eliminated the variability in 383 RMSE across scenarios (compare circles to triangles in Fig. 9). The resulting increase in 384 RMSE was about 0.38 across 30 -day window scenarios when data were present from other 385 streams.

\section{Discussion}


387 We present a statistical model that accounts for many issues that can make stream

388

389

390

391

392

393

394

395

396

397

398

399

400

401

402

403

404

405

406

407

408

409

410

411

412

413

414

415

416

temperature estimation difficult. Our model limits analysis to days when air and water temperature are synchronized, accommodates hysteresis, incorporates time lags, can deal with missing data and autocorrelation and can include external drivers. The result is quite low bias with complete data $\left(\operatorname{RMSE}=0.59^{\circ} \mathrm{C}\right)$, and bias remains low $\left(\operatorname{RMSE}<1^{\circ} \mathrm{C}\right)$ when data from streams or years are missing.

A key feature of our model is a flexible way to identify the portion of days spring-to-fall when daily stream and air temperatures are synchronized. The air-water temperature relationship breaks down during the winter, primarily, due to phase change thermodynamics, insulating ice cover, snow melt, and other physical processes. Previous researchers have omitted modeling winter temperatures or focused solely on summer temperatures (Kanno, Vokoun \& Letcher, 2013; e.g. DeWeber \& Wagner, 2014; Snyder, Hitt \& Young, 2015). However, defining the "winter" period that causes deviations in the airwater relationship depends on the conditions in a specific year and location; therefore, just excluding the winter months based on calendar dates (21 December - 20 March in the northern hemisphere) is an imprecise cutoff with the potential to bias the model and the resulting inference. For example, just as the amount of snow and duration of ice cover differs at $40^{\circ}$ and $45^{\circ}$ latitude, the physical properties that affect the air-water relationship vary annually and from one location to another depending on the exact landscape characteristics of the site, even when compared to nearby locations (Lisi et al., 2015). Additionally, taking the opposite approach and limiting analyses to the summer period excludes large amounts of data and prevents inference during other times of the year, which are important in biological and biogeochemical processes. Our method of calculating the period of the year where the air-water relationship is synchronized alleviates these issues of arbitrarily defining the winter period while maximizing the amount of data available for modeling linear effects of air on stream temperature.

Modeling the synchronized period of the year also provides additional information about the spring and fall breakpoints and the duration between them. Despite considerable random annual variation, we found that air-water relationships were getting synchronized earlier in the spring and remaining synchronized later in the fall. This resulted in a 29 days 
417 per decade expansion in the synchronized period of the year or 44 days over the 15-year

418 study period. This has implications for the growing season (e.g. algal growth, primary

419 productivity, nutrient cycling), which affects invertebrate (Ward \& Stanford, 1982) and

420 vertebrate growth and development (Neuheimer \& Taggart, 2007; Venturelli et al., 2010).

421 Growing seasons worldwide have been expanding about 10-20 days over the last few

422 decades (Linderholm, 2006), which is slower than the expansion in the synchronized

423 period we observed. The relationship between plant-based growing season estimates and

424 the width of the synchronized period is currently unknown, but further model

425 development could help identify links between the width of the synchronized period and

426 other growing-season metrics.

427 Hysteresis is another challenge when modeling stream temperature (Webb \& Nobilis,

428 1997). We allowed for the potential differences in seasonal warming and cooling with a

429 cubic effect of day of the year on water temperature (Figs. 2 \& A4). This can be understood

430 as the average expected water temperature on any day of the year during the synchronized

431 period. Then the effects of air temperature, flow, and site can be thought of as moving the

432 water temperature away from this mean expectation. We also allow this cubic effect to vary

433 randomly by year. This has two major benefits. First, it allows the idiosyncratic seasonal

434 temperature patterns to vary annually (Fig. A4). Otherwise it would be very difficult to

435 have a parametric model describing the effects of a warm, wet spring followed by a cold

436 summer or three moderately cool weeks followed by one extremely hot week in the

437 autumn. The second benefit is, by having a random year effect, the pattern of hysteresis is

438 variable and can be well-described when sufficient data are available, while in years with

439 little data the predictions move towards the mean across years. This borrowing effect

440 allows for good predictions even in years with minimal data. An alternative to the

441 parametric cubic function is a non-parametric smoothed function, but it can be challenging

442 to estimate hierarchical effects for smoothed functions. Li et al. (2014) present a stream

443 temperature model with time-varying smoothed functions which allows parameter

444 estimates to vary over time. The time varying coefficients can account for variation in the

445 air-water temperature relationship that is not included in the model. RMSE estimates $(\sim 1$ 
$446{ }^{\circ} \mathrm{C}$ ) from the time-varying coefficient model are low and similar to the estimate from our 447 model $\left(0.59^{\circ} \mathrm{C}\right)$.

448 Using the cubic function also provides information on the smoothed annual peak 449 temperature and the date of the peak water temperature. We estimated that the peak 450 temperature increased at a rate of $0.63{ }^{\circ} \mathrm{C}$ per decade, or $0.94{ }^{\circ} \mathrm{C}$ over the course of 15 451 years. The stream temperature warming rate is within the range of rates identified in rivers 452 and streams across the US (0.07- $0.77^{\circ} \mathrm{C}$ per decade, Kaushal et al., 2010), three-fold faster 453 than the rate identified using simple linear models in the Chesapeake Bay watershed 0.28 454 ${ }^{\circ} \mathrm{C}$ per decade, Rice \& Jastram, 2014) and twice as fast as warming of lake surface water in 455 456 the summer $\left(0.34{ }^{\circ} \mathrm{C}\right.$ per decade, $0^{\prime}$ Reilly et al. 2015). In contrast to the peak temperature, the day of the year that the peak temperature was reached did not change during the study.

457

458 459

460

461

462

463

464

465

466

467

468

469

470

471

472

473

474
This decoupling between the value of the peak and the day of the peak suggests that increased peak temperatures are not a result of a change in the timing of maximum temperatures, but rather are driven primarily by increased air temperatures.

Our hierarchical approach to modeling handles years and sites with varying amounts of incomplete data. A hierarchical model can accommodate missing data for one year and site by 'borrowing' information from other years and sites (Bolker et al., 2009). We evaluated how missing data influenced prediction bias across years and sites. When data for a single year and all sites were left out, bias (increase in RMSE) was higher (+0.57) than when just the West Brook data were left out $(+0.48)$, demonstrating how data from nearby streams can inform estimates. It will be important in the future to identify the strength of the spatial decay function to understand how close sites (on the network) should be to allow effective information sharing.

We also evaluated how missing data within years influenced predictions. First, we added data from the middle of the year in both directions and found that a $10 \%$ increase in data resulted in approximately a 10\% improvement in RMSE. Clearly, more data during the synchronized period will provide better predictions, but predictions can still be reasonable with limited data during the year. This may be especially true when data from more nearby streams are available, as stream temperature monitoring becomes increasingly common. 
475 Second, we evaluated how data availability during the year affected predictions by

476 retaining 30 days of data and shifting the window of availability across the year. When data

477 were available from the other three streams, WB predictions with missing data were

478 insensitive to the timing of available data (consistent 0.38 increase in RMSE). However,

479 when data from the other three streams were not available, predictions were poorer when

480 data were only available early in the year compared to late in the year. When data are

481 available from nearby streams, the local data can help define the annual cubic pattern in

482 the model, but when they are not available the higher variability in daily stream

483 temperature in the spring compared to the autumn likely results in some years with cubic

484 patterns that are a poor fit to autumn stream temperatures.

485 We used a simple autoregressive term to model the temporal autocorrelation in the

486

487

488

489

490

491

492

493

494

495

496

497

498

499

500

501

502

503

504

residuals. This is critical in a regression-based daily temperature model because the error at time step $i$ is likely to be correlated with the error at time $i+1$ due to some small temporal variation not accounted for by the regression parameters. Any autocorrelation or patterning in the residuals violates the assumptions of a linear regression model. This is a classic problem in time series analysis (Shumway \& Stoffer, 2006). In our model, the AR1 term adequately corrected for temporal autocorrelation such that the resulting residuals displayed homogeneity and were normally distributed. No additional lagging or moving average was needed in this case, but it would be easy to add these additional ARIMA parameters to the model if necessary. The estimate of $0.79 \pm 0.05$ (mean \pm s.d., Table S1) for the autoregressive term indicates strong effect of the previous day's residual on stream temperature.

Air temperature can be used as the primary variable predicting water temperature in small streams. However, additional factors can influence water temperature directly or affect the air-water temperature relationship (Caissie, 2006; Sun et al., 2014). We found that the effect of air temperature was reduced as stream flow increased (significant negative coefficient; Appendix S1). This corresponds to our expectations because a larger volume of water will require more energy to heat and at high flows the streams are generally deeper resulting in a lower relative surface area in contact with the air. Additionally, higher flow is often a result of surface and ground water inputs originating over the previous days and 
505 weeks and therefore less influenced by the current air temperature. Here, flow was our 506 only external variable. Our model structure can easily accommodate additional factors such 507 as forest cover, agriculture, impervious surfaces, impoundments, and ground water when 508 these data are available and vary over the streams of interest. Incorporating groundwater 509 data at broad spatial scales, however, remains a substantial challenge due to a lack of a 510 consistent, accurate data layer. The model could also easily be extended to model daily 511 minimum (Hughes, Subba Rao \& Subba Rao, 2007) or maximum (Caissie, El-jabi \& Satish, 512 2001; Li et al., 2014) stream temperature in addition to the daily mean modeled here.

513 Local variation of environmental drivers at very small spatial scales can have a strong 514 influence on stream temperatures. For example, ground water input can moderate air 515 temperature effects in the summer and winter (Poole \& Berman, 2001; Kanno, Vokoun \&

516 Letcher, 2013; Westhoff \& Paukert, 2014; Snyder, Hitt \& Young, 2015). We did not model

517 groundwater effects because we lack information on the spatial distribution of

518 groundwater inputs in our small system, but we did observe marked differences in water

519 temperature across streams (Fig. 4). Water temperatures in the WB and OS were

520

521

522

523

524

525

526

527

528

529

530

531

532

533

534 considerably warmer than temperatures in OL and IL. Stream-specific intercepts reflect the raw stream temperature data, with a range of $1{ }^{\circ} \mathrm{C}$ across streams (stream-specific parameters in Table S1). The most likely explanation for the temperature differences is the presence of upstream impoundments (Webb \& Walling, 1996; Dripps \& Granger, 2013); the warmer streams have either an upstream reservoir with a surface release (WB) or a beaver impoundment (OS). The cooler streams do not have any impounded water. Even small temperature differences among streams can have important consequences for production and phenology of stream biota (Quinn et al., 1994; Miller et al., 2011; Wheeler et al., 2014; Letcher et al., 2015), reinforcing the value of statistically robust stream temperature models.

By accounting for many of the issues that make stream temperature estimation difficult, our stream temperature model provides robust estimates with low error. Most current stream temperature models do not address all of these issues and generally report higher error rates, especially models of daily stream temperature. One reason error rates of our model are low is that we limit analysis to the synchronized period, but this has the added 
535 benefit of generating data for the beginning and end of the synchronized period which can 536 be very useful for evaluating shifting stream phenology. Our model can also accommodate 537 missing data which, unfortunately, is common in streams as temperature logger availability 538 limits data to incomplete spatial coverage and often incomplete temporal coverage within a 539 year. The structure of our model is flexible enough that a data time series even as short as 54010 days can contribute important information.

541 
542 References

543 Beauchene M, Becker M, Bellucci CJ, Hagstrom N, Kanno Y. 2014. Summer Thermal

544 Thresholds of Fish Community Transitions in Connecticut Streams. North American

545 Journal of Fisheries Management 34:119-131.

546 Benyahya L, Caissie D, St-Hilaire A, Ouarda TBM., Bobée B. 2007. A Review of Statistical

547 Water Temperature Models. Canadian Water Resources Journal 32:179-192.

548 Benyahya L, St-Hilaire A, Ouarda TBMJ, Bobée B, Dumas J. 2008. Comparison of non-

549 parametric and parametric water temperature models on the Nivelle River, France.

550 Hydrological Sciences Journal 53:640-655.

551 Bolker BM, Brooks ME, Clark CJ, Geange SW, Poulsen JR, Stevens MHH, White J-SS. 2009.

552 Generalized linear mixed models: a practical guide for ecology and evolution. Trends in 553 Ecology \& Evolution 24:127-35.

554 Brooks S, Gelman A. 1998. General methods for monitoring convergence of iterative 555 simulations. Journal of Computational and Graphical Statistics7:434-455.

556 Brown GW. 1969. Predicting temperatures of small streams. Water Resources Research $557 \quad 5: 68-75$.

558 Caissie D. 2006. The thermal regime of rivers: a review. Freshwater Biology 51:1389-1406.

559 Caissie D, El-jabi N, Satish MG. 2001. Modelling of maximum daily water temperatures in a $560 \quad$ small stream. Journal of Hydrology 251:14-28.

561 Caissie D, El-Jabi N, St-Hilaire A. 1998. Stochastic modelling of water temperatures in a 562 small stream using air to water relations. Canadian Journal of Civil Engineering $563 \quad 25: 250-260$. 
564 Crisp DT, Howson G. 1982. Effect of air temperature upon mean water temperature in 565 streams in the north Pennines and English Lake District. Freshwater Biology 12:359566367.

567

568

569

570

571

572

573

574

575

576

577

578

579

580

581

582

583

584

585

586

DeWeber JT, Wagner T. 2014. A regional neural network ensemble for predicting mean daily river water temperature. Journal of Hydrology 517:187-200.

Dripps W, Granger SR. 2013. The impact of artificially impounded, residential headwater lakes on downstream water temperature. Environmental Earth Sciences 68:23992407.

Eby L., Helmy O, Holsinger LM, Young MK. 2014. Evidence of Climate-Induced Range Contractions in Bull Trout Salvelinus confluentus in a Rocky Mountain Watershed, U.S.A. PLOS ONE 9:e98812.

Elliott JM, Elliott JA. 2010. Temperature requirements of Atlantic salmon Salmo salar, brown trout Salmo trutta and Arctic charr Salvelinus alpinus: predicting the effects of climate change. Journal of Fish Biology 44:1-25.

Erickson TR, Stefan HG. 2000. Linear Air/Water Temperature Correlations for Streams during Open Water Periods. Journal of Hydrologic Engineering 5:317-321.

Fry F. 1971. The effect of environmental factors on the physiology of fish. In: Fish physiology: environmental relations and behaviour. New York: Academic Press, 1-98.

Gelman A, Hill J. 2007. Data analysis using regression and multilevel/hierarchical models. Cambridge University Press.

Hague MJ, Patterson DA. 2014. Evaluation of Statistical River Temperature Forecast Models for Fisheries Management. North American Journal of Fisheries Management 34:132146. 
587 Hawkins CP, Hogue JN, Decker LM, Feminella JW. 1997. Channel morphology, water 588 temperature, and assemblage structure of stream insects. Journal of the North 589 American Benthological Society1 16:728-749.

590 Hayhoe K, Wake CP, Huntington TG, Luo L, Schwartz MD, Sheffield J, Wood E, Anderson B, 591 Bradbury J, DeGaetano A, Troy TJ, Wolfe D. 2007. Past and future changes in climate 592

593 594 595 and hydrological indicators in the US Northeast. Climate Dynamics 28:381-407.

Hilderbrand RH, Kashiwagi MT, Prochaska AP. 2014. Regional and local scale modeling of stream temperatures and spatio-temporal variation in thermal sensitivities. Environmental Management 54:14-22.

Hill R a., Hawkins CP, Carlisle DM. 2013. Predicting thermal reference conditions for USA streams and rivers. Freshwater Science 32:39-55.

Hughes GL, Subba Rao S, Subba Rao T. 2007. Statistical analysis and time-series models for minimum/maximum temperatures in the Antarctic Peninsula. Proceedings of the Royal Society A: Mathematical, Physical and Engineering Sciences 463:241-259.

Huntington TG, Richardson AD, McGuire KJ, Hayhoe K. 2009. Climate and hydrological changes in the northeastern United States: recent trends and implications for forested and aquatic ecosystemsThis article is one of a selection of papers from NE Forests 2100: A Synthesis of Climate Change Impacts on Forests of th. Canadian Journal of Forest Research 39:199-212.

Isaak DJ, Peterson EE, Ver Hoef JM, Wenger SJ, Falke J a., Torgersen CE, Sowder C, Steel EA, Fortin M-J, Jordan CE, Ruesch AS, Som N, Monestiez P. 2014. Applications of spatial statistical network models to stream data. Wiley Interdisciplinary Reviews: Water: doi 10.1002/wat2.1023Isaak DJ, Hubert WA. 2001. A hypothesis about factors that affect maximum summer stream temperatures across montane landscapes. Journal of the American Water Resources Association 37:351-366. 
612 Isaak DJ, Rieman BE. 2012. Stream isotherm shifts from climate change and implications for 613 distributions of ectothermic organisms. Global Change Biology:742-751.

614 Kanno Y, Vokoun JC, Letcher B. 2013. Paired stream-air temperature measurements reveal 615 fine-scale thermal heterogeneity within headwater brook trout streams networks. 616 River Research and Applications 10.1002/rr.

617 Kaushal SS, Likens GE, Jaworski N a, Pace ML, Sides AM, Seekell D, Belt KT, Secor DH, 618 Wingate RL. 2010. Rising stream and river temperatures in the United States. Frontiers 619 in Ecology and the Environment 8:461-466.

620

621

622

623

624

625

626

627

628

629

630

631

632

633

634

635

636

Kim K, Chapra S. 1997. Temperature model for highly transient shallow streams. Journal of Hydraulic Engineering 123:30-40.

Letcher BH, Schueller P, Bassar RD, Nislow KH, Coombs JA, Sakrejda K, Morrissey M, Sigourney DB, Whiteley AR, O’Donnell MJ, Dubreuil TL. 2015. Robust estimates of environmental effects on population vital rates: an integrated capture-recapture model of seasonal brook trout growth, survival and movement in a stream network. Journal of Animal Ecology 84:337-352.

Li H, Deng X, Kim D-Y, Smith EP. 2014. Modeling maximum daily temperature using a varying coefficient regression model. Water Resources Research 50:3073-3087.

Linderholm HW. 2006. Growing season changes in the last century. Agricultural and Forest Meteorology 137:1-14.

Lisi PJ, Schindler DE, Cline TJ, Scheuerell MD, Walsh PB. 2015. Watershed geomorphology and snowmelt control stream thermal sensitivity to air temperature. Geophysical Research Letters 42:3380-3388.

Miller MR, Brunelli JP, Wheeler P a., Liu S, Rexroad CE, Palti Y, Doe CQ, Thorgaard GH. 2011. A conserved haplotype controls parallel adaptation in geographically distant salmonid populations. Molecular Ecology: 10.1111/j.1365-294X.2011.05305.x. 
637 Mohseni O, Stefan HG, Erickson TR. 1998. A nonlinear regression model for weekly stream 638 temperatures. Water Resources Research 34:2685-2692.

639 Morrill JC, Bales RC, Conklin MH. 2005. Estimating stream temperature from air 640 temperature: Implications for future water quality. Journal of Environmental $641 \quad$ Engineering-Asce 131:139-146.

642 Neuheimer AB, Taggart CT. 2007. The growing degree-day and fish size-at-age: the 643 overlooked metric. Canadian Journal of Fisheries and Aquatic Sciences 64:375-385.

644 Nielsen JP. 1999. Record extension and streamflow statistics for the Pleasant River, Maine. 645 US Department of the Interior, US Geological Survey Information Services. Available at: 646 http://me.water.usgs.gov/reports/finalreport.pdf.

647 O'Reilly CM, et al.. 2015. Rapid and highly variable warming of lake surface waters around the 648 globe. Geophysical Research Letters:773-781.

649 Peterson EE, Ver Hoef JM. 2010. A mixed-model moving-average approach to geostatistical 650 modeling in stream networks. Ecology 91:644-51.

651 Pilgrim JM, Fang X, Stefan HG. 1998. Stream Temperature Correlations With Air 652 Temperatures in Minnesota: Implications for Climate Warming. Journal of the 653 American Water Resources Association 34:1109-1121.

654 Plummer M, Nest N, Cowles K, Vines K. 2006. CODA: convergence diagnosis and output 655 analysis for MCMC. R News 6:7-11.

656 Plummer M. 2014. rjags: Bayesian graphical models using MCMC.

657 Poole GC, Berman CH. 2001. An ecological perspective on in-stream temperature: Natural 658 heat dynamics and mechanisms of human-caused thermal degradation. Environmental $659 \quad$ Management 27:787-802. 
660 Quinn J, Steele G, Hickey C, Vickers M. 1994. Upper thermal tolerances of twelve $661 \quad$ NewZealand stream invertrbrate species. New Zealand Journal of Marine and $662 \quad$ Freshwater Reserach 28:391-397.

663 Rice KC, Jastram JD. 2014. Rising air and stream-water temperatures in Chesapeake Bay 664 region, USA. Climatic Change.

665

666

667

668

669

670

671

672

673

674

675

676

677

678

679

680

681

682

683

684

Rushworth a. M, Peterson EE, Ver Hoef JM, Bowman a. W. 2015. Validation and comparison of geostatistical and spline models for spatial stream networks. Environmetrics..

Shumway RH, Stoffer DS. 2006. Time Series Analysis and Its Applications: With R Examples. Springer Science+Business Media.

Sinokrot B a., Stefan HG. 1993. Stream temperature dynamics: measurements and modeling. Water Resources Research 29:2299-2312.

Smith K, Lavis M. 1975. Environmental influences on the temperature of a small upland stream. Oikos 26:228-236.

Snyder C, Hitt N, Young J. 2015. Accounting for groundwater in stream fish thermal habitat responses to climate change. Ecological Applications 25:1397-1419.

Stefan HG, Preud'homme EB. 1993. Stream temperature estimation from air temperature. Water Resources Bulletin 29:27-45.

Sun N, Yearsley J, Voisin N, Lettenmaier DP. 2014. A spatially distributed model for the assessment of land use impacts on stream temperature in small urban watersheds. Hydrological Processes 2345: 2331-2345.

Taylor RG, Scanlon B, Doll P, Rodell M, van Beek R, Wada Y, Longuevergne L, Leblanc M, Famiglietti JS, Edmunds M, Konikow L, Green TR, Chen J, Taniguchi M, Bierkens MFP, MacDonald A, Fan Y, Maxwell RM, Yechieli Y, Gurdak JJ, Allen DM, Shamsudduha M, Hiscock K, Yeh PJ-F, Holman I, Treidel H. 2013. Ground water and climate change. Nature Clim. Change 3:322-329. 
685 Venturelli P a., Lester NP, Marshall TR, Shuter BJ. 2010. Consistent patterns of maturity and 686 density-dependent growth among populations of walleye (Sander vitreus): application 687 of the growing degree-day metric. Canadian Journal of Fisheries and Aquatic Sciences $688 \quad 67: 1057-1067$.

689 690 691 692 693 694 695 696 697 698 699 700

Wagner T, Hayes DB, Bremigan MT. 2006. Accounting for Multilevel Data Structures in Fisheries Data using Mixed Models. Fisheries 31:180-187.

Ward J V, Stanford JA. 1982. Thermal Responses in the Evolutionary Ecology of Aquatic Insects. Annual Review of Entomology 27:97-117.

Webb B. 1996. Trends in stream and river temperature. Hydrological Processes 10:205226.

Webb BW, Hannah DM, Moore RD, Brown LE, Nobilis F. 2008. Recent advances in stream and river temperature research. Hydrological Processes 22:902-918.

Webb BW, Clack PD, Walling DE. 2003. Water-air temperature relationships in a Devon river system and the role of flow. Hydrological Processes 17:3069-3084.

Webb BW, Nobilis F. 1997. A long term perspective on the nature of the air-water temperature relationship: A case study. Hydroogical. Processes. 11:137-147.

Webb JA, Stewardson MJ, Koster WM. 2010. Detecting ecological responses to flow variation using Bayesian hierarchical models. Freshwater Biology 55:108-126.

Webb B, Walling D. 1996. Long-term variability in the thermal impact of river impoundment and regulation. Applied Geography 16:211-223.

Wenger SJ, Isaak DJ, Luce CH, Neville HM, Fausch KD, Dunham JB, Dauwalter DC, Young MK, Elsner MM, Rieman BE, Hamlet a. F, Williams JE. 2011. Flow regime, temperature, and biotic interactions drive differential declines of trout species under climate change. Proceedings of the National Academy of Sciences:1-6. 
709 Westhoff JT, Paukert CP. 2014. Climate change simulations predict altered biotic response 710 in a thermally heterogeneous stream system. PloS one 9:e111438.

711 Wheeler CA, Bettaso JB, Ashton DT, Welsh HH. 2014. Effects of water temperature on 712 breeding phenology, growth, and metamorphosis of foothill yellow-legged frogs ( Rana

713 boylii ): a case study of the regulated mainstem and unregulated tributaries of $714 \quad$ California's trinity river. River Research and Applications 24.

715 Xu CL, Letcher BH, Nislow KH. 2010. Context-specific influence of water temperature on 716 brook trout growth rates in the field. Freshwater Ecology 55:2342-2369.

717 Younus M, Hondzo M, Engel B. 2000. Stream temperature dynamics in upland agricultural 718 watersheds. Journal of Environmental Engineering:618-628. 


\section{Tables}

721 Table 1.Landscape variables for the four study streams (Fig. 1).

722

\begin{tabular}{|c|c|c|c|c|c|c|c|c|}
\hline Stream & Abbrev. & $\begin{array}{l}\text { Watershed } \\
\text { area }\left(\mathrm{km}^{2}\right)\end{array}$ & $\begin{array}{l}\text { Impounded } \\
\text { area (\%) }\end{array}$ & $\begin{array}{l}\text { Watershed } \\
\text { forested } \\
(\%)\end{array}$ & $\begin{array}{l}\text { Watershed } \\
\text { developed } \\
(\%)\end{array}$ & $\begin{array}{l}\text { Agriculture } \\
(\%)\end{array}$ & $\begin{array}{l}\text { Mean } \\
\text { elevation } \\
\text { (m) }\end{array}$ & $\begin{array}{l}\text { Mean } \\
\text { slope } \\
(\%)\end{array}$ \\
\hline $\begin{array}{l}\text { West } \\
\text { Brook }\end{array}$ & WB & 11.8 & 2.62 & 92.0 & 2.9 & 3.0 & 164.8 & 13.02 \\
\hline $\begin{array}{l}\text { Open } \\
\text { Large }\end{array}$ & OL & 2.5 & 0.75 & 88.6 & 2.8 & 7.7 & 226.1 & 14.75 \\
\hline $\begin{array}{l}\text { Open } \\
\text { Small }\end{array}$ & OS & 1.0 & 2.94 & 99.1 & 0.0 & 0.0 & 211.0 & 16.46 \\
\hline $\begin{array}{l}\text { Isolated } \\
\text { Large }\end{array}$ & IL & 1.4 & 0.58 & 95.5 & 1.6 & 2.9 & 232.9 & 16.15 \\
\hline
\end{tabular}


725

726

727

\begin{tabular}{rrrrr} 
& West & $\begin{array}{r}\text { Open } \\
\text { Large }\end{array}$ & $\begin{array}{r}\text { Open } \\
\text { Small }\end{array}$ & Isolated \\
& Large \\
\hline 1999 & 233 & 0 & 0 & 0 \\
2000 & 256 & 0 & 0 & 0 \\
2001 & 230 & 0 & 0 & 0 \\
2002 & 237 & 0 & $81(58)$ & 0 \\
2003 & 191 & $179(4)$ & $183(2)$ & 180 \\
2004 & 222 & $214(3)$ & $215(1)$ & 214 \\
2005 & 235 & 203 & $102(52)$ & 200 \\
2006 & 210 & 0 & $83(59)$ & 214 \\
2007 & 0 & 192 & 204 & 192 \\
2008 & $121(45)$ & 198 & 199 & 197 \\
2009 & 0 & 243 & 251 & 247 \\
2010 & 273 & 245 & 265 & 246 \\
2011 & 233 & 205 & 248 & 205 \\
2012 & 210 & 234 & 237 & 235 \\
2013 & 226 & 218 & 0 & 212
\end{tabular}


730
Table 3. Root mean square error $\left(\mathrm{RMSE},{ }^{\circ} \mathrm{C}\right)$ for various scenarios described in the text. The scenarios involved a training dataset and a test dataset (data left out).

\begin{tabular}{lllll}
\hline All data & $0.59 \pm 0.09$ & - & - & - \\
$30 \%$ data & $0.69 \pm 0.003$ & All & $0.86 \pm 0.010$ & 0.17 \\
randomly & & & & \\
left out & & West Brook & $1.07 \pm 0.26$ & 0.48 \\
For each & $0.59 \pm 0.09$ & & & \\
year, West & & & & \\
Brook left & & & & \\
out & & & & \\
For each & $0.59 \pm 0.09$ & All & & \\
year, all & & &
\end{tabular}


733 Fig. 1. Map of the study area. Dots indicate locations of temperature loggers and shading 734 represents elevation (range approximately $100 \mathrm{~m}-250 \mathrm{~m}$ ).

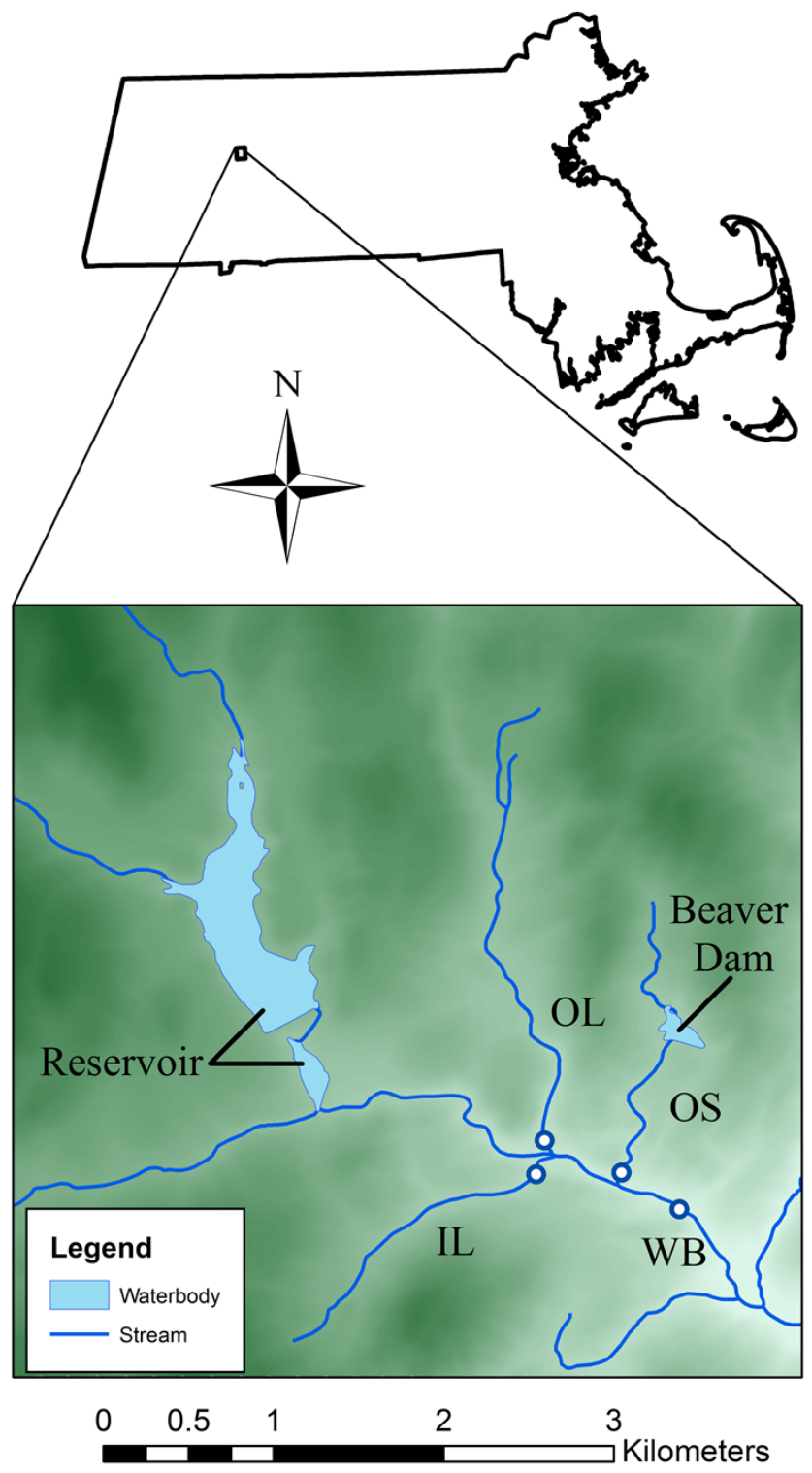




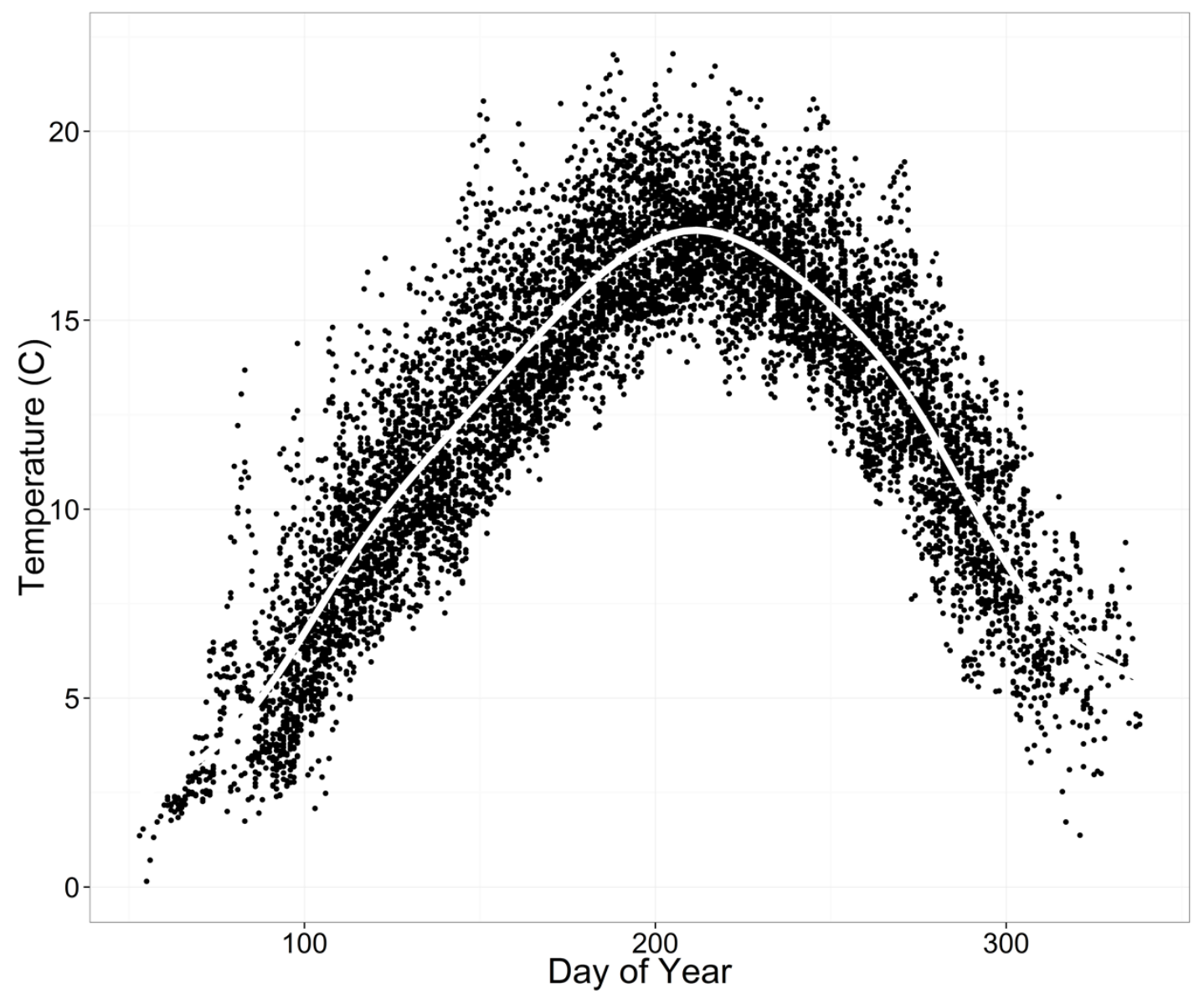

737

Fig. 2. Water temperature data (daily means) from all sites and years overlain by a spline (white line). 

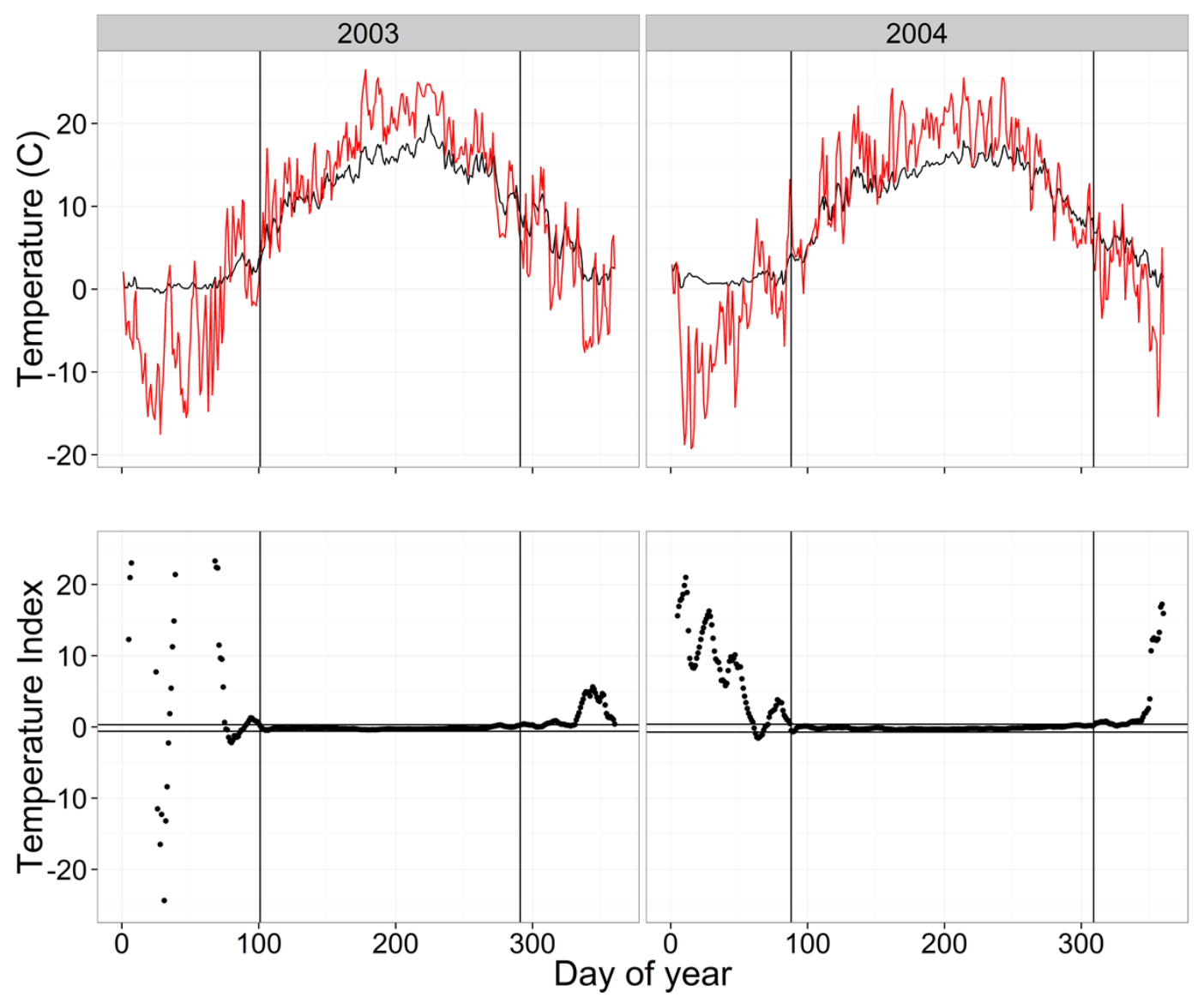

Fig. 3. Examples of raw air (red) and water (black) temperatures from the WB (above) and the temperature index (below) used to calculate the temperature breakpoints (vertical lines). Horizontal lines in the lower panels are the $99 \%$ confidence intervals of the temperature index for day of year 125 to 275 . Vertical axis on the lower panels are truncated to -20 to 20. 


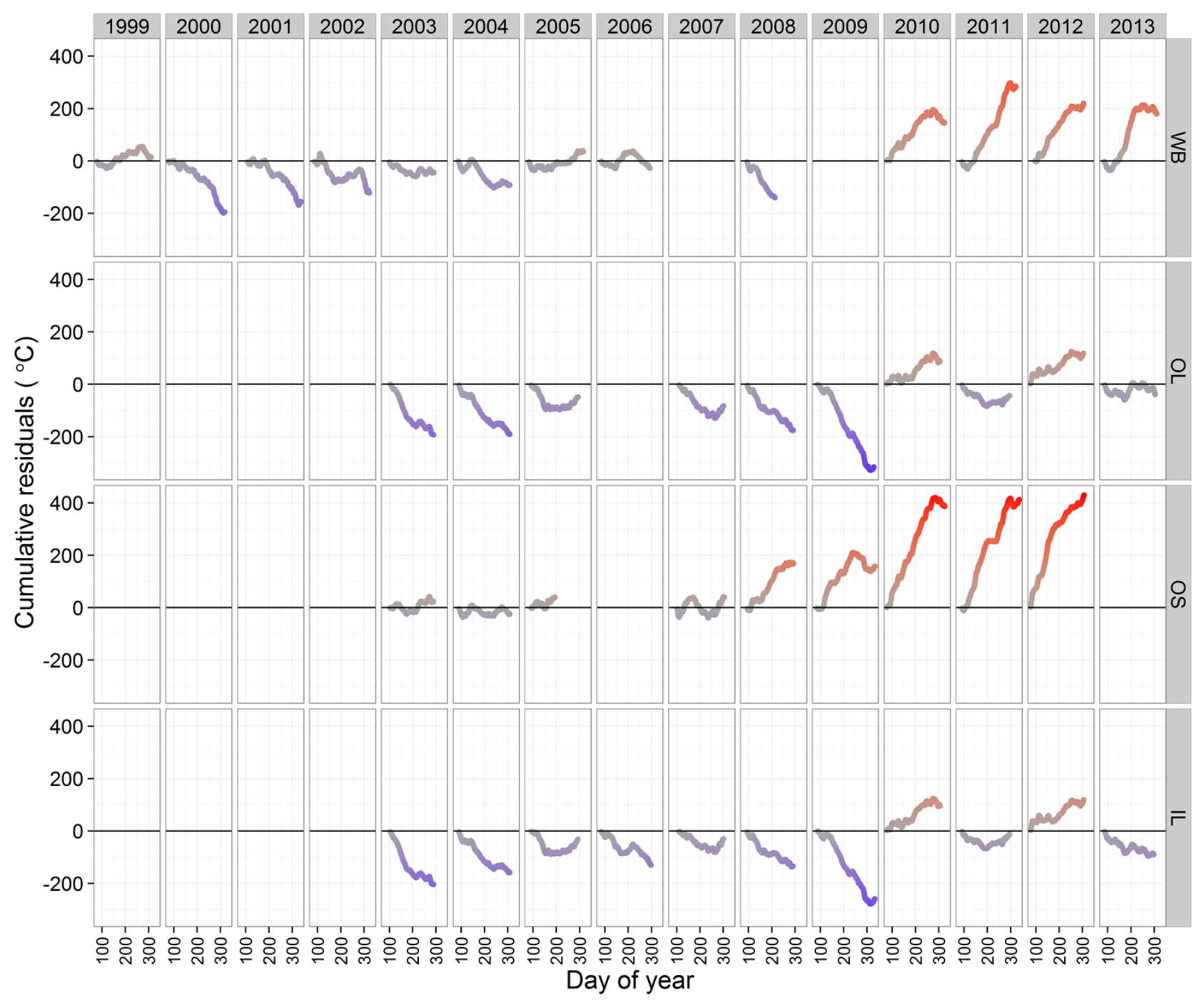

746 Fig. 4. Cumulative residuals from the spline in Fig. 2 for each site and year combination. Curves on or near the horizontal line

indicate 'typical' years whereas curves above the line indicate warm years and below the line indicate cool years. 

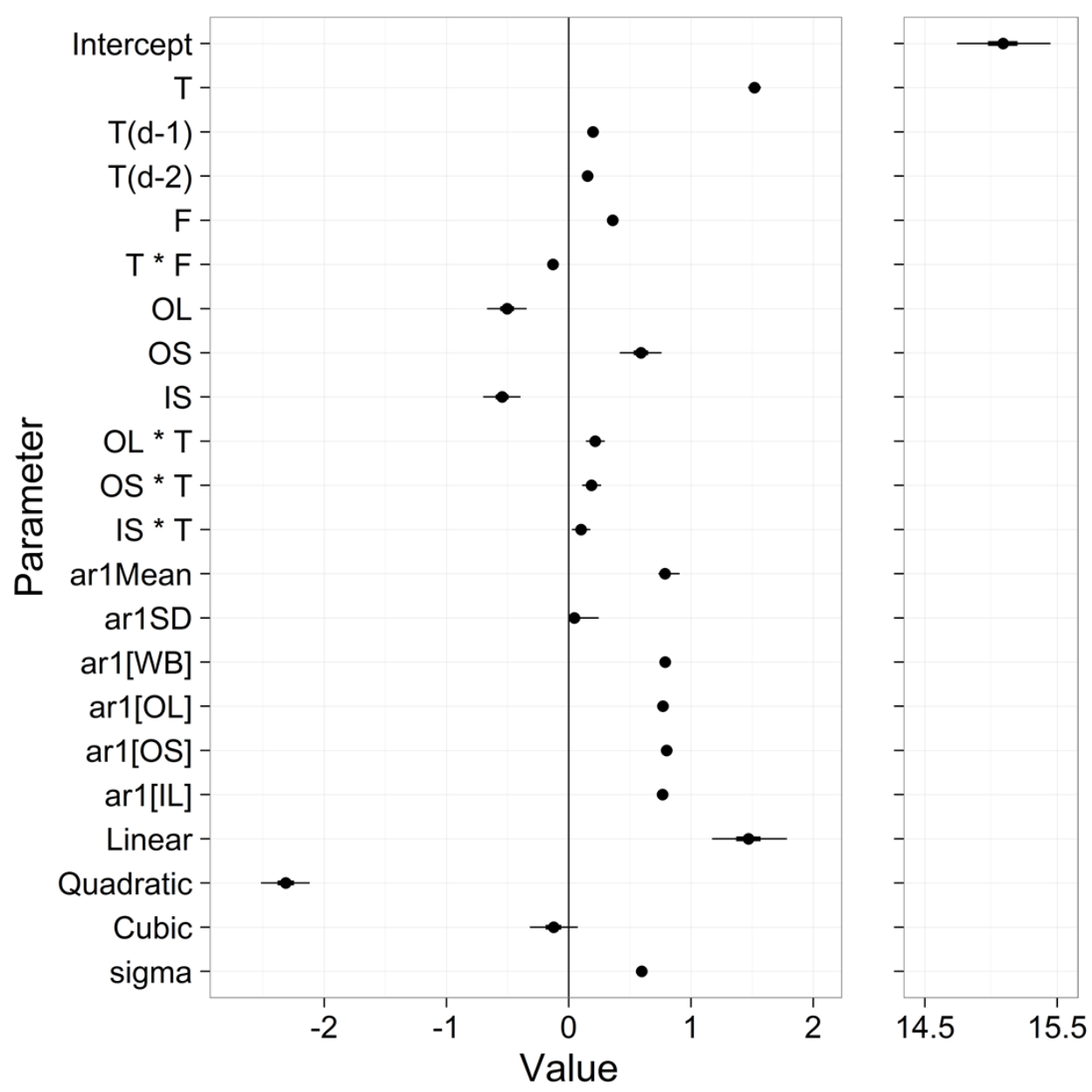

749 Fig. 5. Parameter estimates from the stream temperature model. 'T' stands for temperature, 'F' stands for flow, and OL, OS, IL are rivers. The first 12 rows represent the $\beta_{x}$ in Eq. 5. 'ar1[x]' are the $\delta_{x}$ from Eq. 3, and the 'Linear', 'Quadratic' and Cubic' parameters are the $\mu Y_{x}$ from Eq. 7. 'sigma' is the residual standard deviation from Eq. 1. 


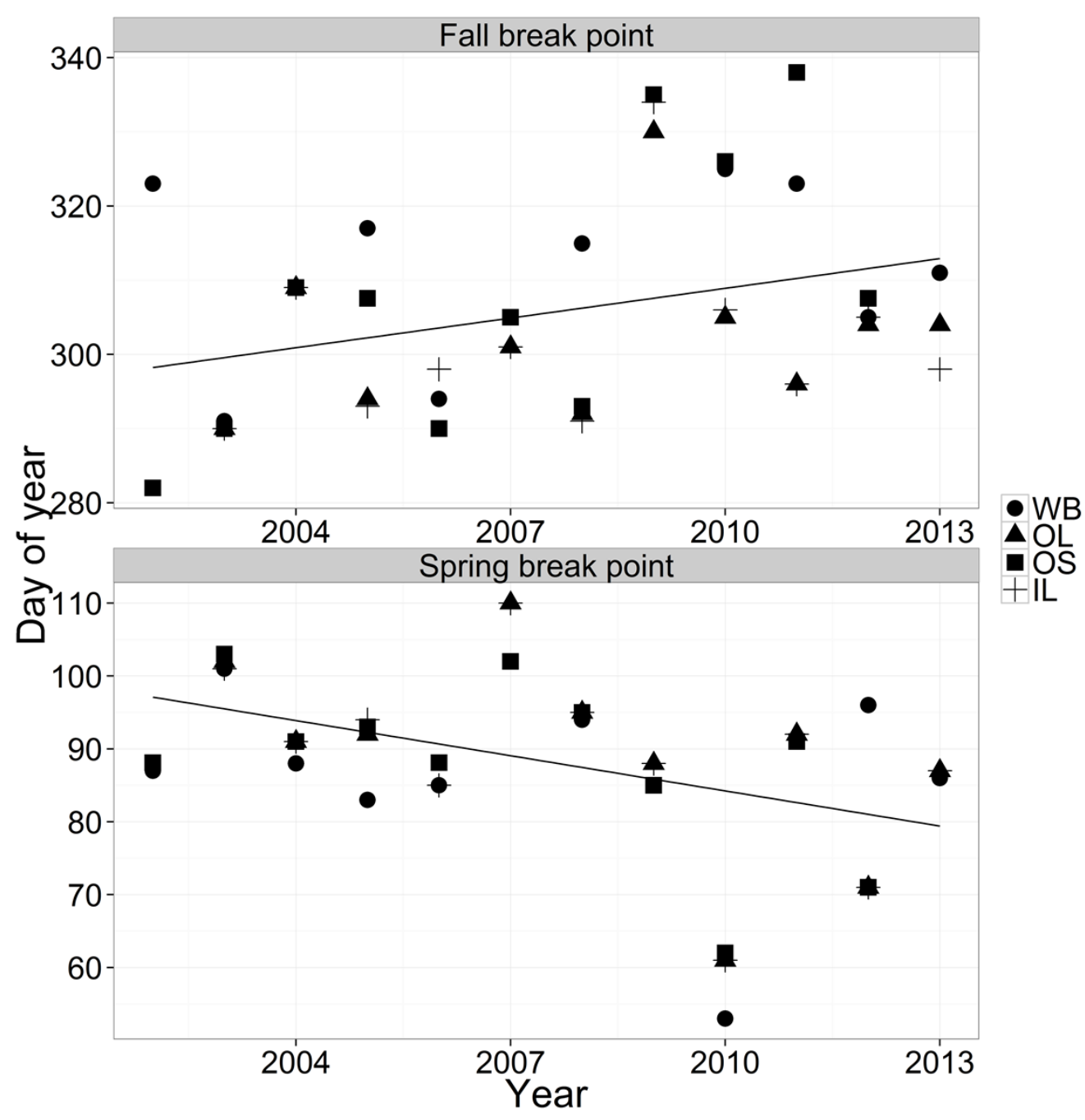

754 Fig. 6. Fall and spring breakpoints across years for the four streams. 

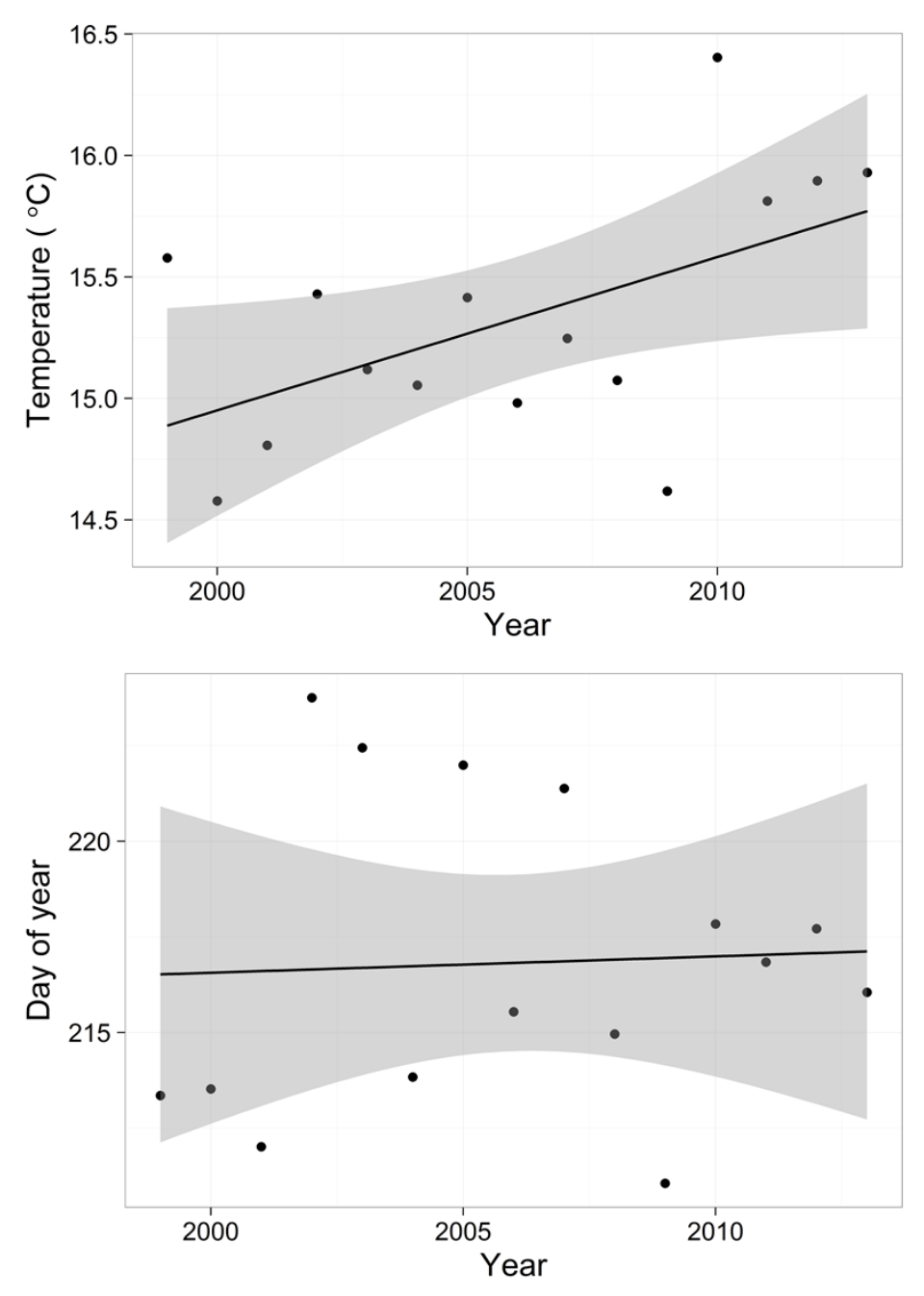

756 Fig. 7. Predicted maximum temperature for each year (y axis value of dot in Fig. S4) and predicted day of the maximum 757 temperature ( $x$ axis value of dot in Fig. S4). 


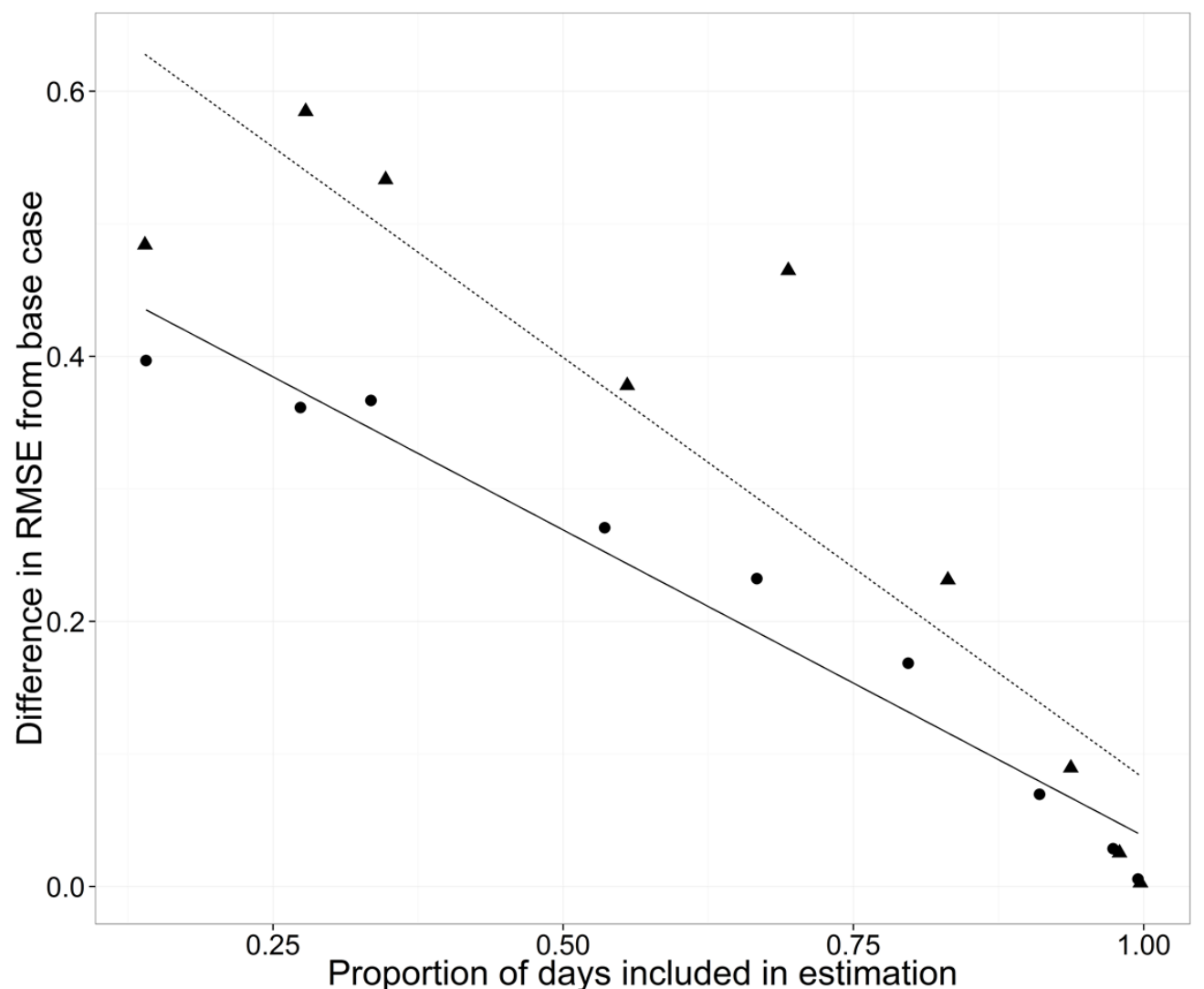

759 Fig. 8. Root mean square error (RMSE) difference from the base case (all data included) for the WB for the cross-validation analyses changing the proportion of days included in estimation. Estimation data included either no data from any of the 761 streams for each year (triangles, dashed line) or data from the three other streams but no data for the WB for each year 762 (circles, solid line). 


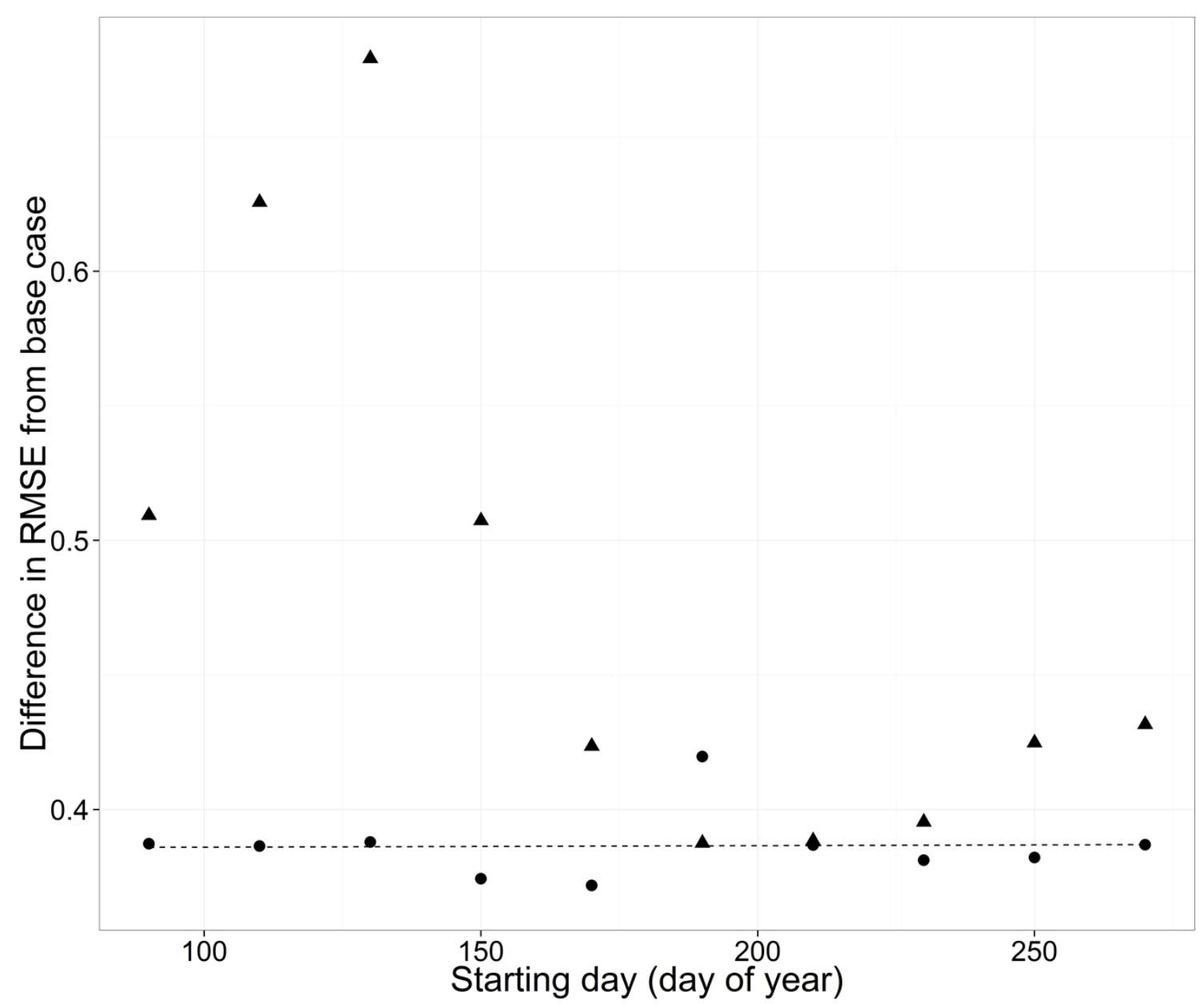

765 Fig. 9. Root mean square error (RMSE) difference from the base case (all data included) for the WB for the cross-validation 766 analyses changing the starting day of a non-overlapping 30-d moving window. Estimation data included either no data from 767 any of the streams for each year (triangles) or data from the three other streams but no data for the WB for each year (circles, 768 solid line). 